Final submitted and accepted version

Sevisari, U. \& Reichenberger, I. (2020). Value co-creation in Couchsurfing - the Indonesian host perspective. International Journal of Culture, Tourism and Hospitality Research, 14(4), 473-488. 


\title{
Value Co-Creation in Couchsurfing - The Indonesian Host Perspective
}

\author{
Abstract: \\ Purpose:
}

Collaborative consumption experiences in tourism have been examined widely, yet predominantly focused on guest perspectives. Using the sharing economy platform Couchsurfing, this study utilizes value co-creation to explore hosting experiences in non-monetary accommodation sharing in a developing country, including hosts' motivations to participate, the range of social practices during hosting, and the value outcomes achieved through hosting.

Methodology:

Based on a social constructivist paradigm, 20 in-depth interviews and one focus group were conducted with experienced Couchsurfing hosts in Indonesia.

Findings:

Findings highlight the exclusively intrinsic nature of hosts' motivations and their subsequent impact on co-creational practices and value outcomes. Social practices revolve around the establishment and acquisition of social and cultural capital and providing guests with authentic local and cultural tourist experiences. Hosts reported value outcomes relating to friendship, knowledge, an improved sense of self, and employment opportunities.

Research Limitations/Implications:

Results of this research may not be transferable to Western accommodation sharing settings or more rural and less touristically developed regions within developing countries.

Social Implications:

It is argued that hosting can contribute positively to host communities in developing countries by facilitating intercultural communication and knowledge transfer while enhancing cultural self-identity and professional advancement.

Originality/Value:

The majority of existing research on accommodation sharing has examined guest perspectives while being placed within predominantly Western contexts. This paper adds new knowledge by exploring the host perspective and examining the impacts of the sharing economy in a developing country.

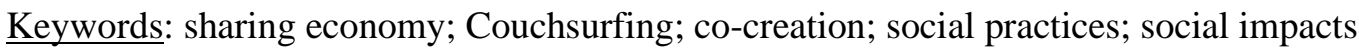




\section{Introduction}

Over the past decade, tourism and hospitality academia has seen an increase in sharing economy related research. The majority of studies focused on accommodation sharing providers, especially Airbnb (e.g. Camilleri and Neuhofer, 2017, Guttentag, 2015, Lampinen and Cheshire, 2016) and Couchsurfing (e.g. Decrop et al., 2017, Molz, 2012, Geiger et al., 2018) and subsequently the perspective and experiences of guests (e.g. Brochado et al., 2017, Guttentag et al., 2018, Johnson and Neuhofer, 2017, Kim et al., 2018, Möhlmann, 2015). Comparatively little information is available on hosts - a surprising gap, considering that the authentic tourism experiences the sharing economy is suggested to support are built upon encounters between guests and hosts (Johnson and Neuhofer, 2017). Further, most existing sharing accommodation research is firmly placed within Western contexts (Molz, 2012), and calls for greater variety amongst cultural contexts were made (Cheng, 2016, Chen, 2012). These gaps limit our understanding of the global relevance and impacts of the sharing economy in a variety of ways: First, by neglecting one crucial stakeholder within what is essentially a collaborative context, we are unable to fully understand the implications, challenges, and potential of this industry for the supply side, destinations, and local communities. Second, emerging regions and countries are experiencing rapid tourism growth, yet are placed within significantly different cultural and economic contexts where the sharing economy and participation in it may hold different meanings that are yet to be fully understood.

This paper aims to fill this research gap by examining host experiences in accommodation sharing, specifically in the context of the non-monetary platform 'Couchsurfing' in Indonesia. It is argued that social encounters are especially important in non-monetary collaborative sharing settings where the financial incentive is removed (Böcker and Meelen, 2017, Jung et al., 2016). Couchsurfing thus provides a suitable context within which to explore the dimensions of the host perspective in more depth. Exploring these themes in Indonesia, a developing country with an often strong focus on community-based tourism (Ernawati et al., 2017), will allow for an exploration of the role of the tourism sharing economy for host communities in previously neglected settings. This subsequently contributes insight into the potential of accommodation sharing for community participation in tourism. Picard and Buchberger (2013) already asked 'Why would people let complete strangers stay at their houses, often leaving them with the keys and not charging them a penny?' This paper answers this question for Couchsurfing hosts in Indonesia by exploring their hosting motivations and experiences. Drawing upon the concept of value co-creation, we examine hosts' motivations for hosting Couchsurfers, explore the social practices with guests during hosting, and the value outcomes hosts achieve throughout the process. In doing so we fill a pertinent research gap in the accommodation sharing literature, which hitherto has focused strongly on guest perspectives. By providing additional insight into the host perspective we contribute to a more comprehensive picture that acknowledges the roles and contributions of all social actors within the sharing economy experience. Especially the value outcomes 
of Couchsurfing for hosts will be of interest, as only limited insight exists into the sharing economy's social impacts (Cheng, 2016).

This paper will begin with a succinct overview of tourism in Indonesia, accommodation sharing and Couchsurfing in tourism research, followed by the theoretical framework of value co-creation in socio-psychological contexts. After discussing the qualitative methodology, findings are presented and discussed. The paper closes with a conclusion that outlines directions for future research.

\section{Literature Review}

\section{Tourism and the Sharing Economy in Indonesia}

Before examining current research on accommodation sharing, Couchsurfing, and value cocreation, it is necessary to first explore Indonesia as the context for this research. Tourism has become one of the leading sectors of the economy in Indonesia, with 13.4 million international tourist arrivals in 2018 and a 6\% contribution to the country's GDP (UNWTO, 2020). It has experienced a rapid growth rate of an average of $8 \%$ per year over the last 10 years, at times double the growth of the global average (World Travel \& Tourism Council, 2019). The spatial and geographic distribution of the country across several islands makes it at times challenging to cohesively explore national tourism developments. Larger tourism centres such as Bali, where tourism is suggested to contribute up to $80 \%$ to the GDP (Cole, 2012), have been relying on and developing tourism for decades. They are now suffering from negative environmental (Lee and Syah, 2018) as well as socio-cultural (Hillman et al., 2017) impacts. More rural regions, on the other hand, are only just beginning to tap into the potential of tourism, often through community-based sustainable development strategies (Lasso and Dahles, 2018, Towner and Milne, 2017). As of yet, no research has examined how Indonesians engage with tourism-related sharing economy and how this impacts the host community. However, several insights shed light on tourismrelated challenges the host community is facing and therefore offer opportunities for further positive impacts through especially accommodation sharing. The higher the host community's involvement in tourism and the higher their economic benefit, the more positive their attitude towards the industry (Saufi et al., 2014, Towner and Milne, 2017, Walpole and Goodwin, 2001). Yet many Indonesian residents find that the economic benefits of tourism are unequally distributed (Graci, 2017). Many find it challenging to participate in the growing tourism industry and subsequently access its benefits due to a lack of skills (Towner and Milne, 2017), challenges in communicating with visitors, and a perceived inauthentic representation of culture by the tourism industry (Saufi et al., 2014). Ernawati et al. (2017) also found that Indonesian hosts within community-based tourism often lack confidence in sharing attractions as well as culture with visitors. They suggest that host community perception of and participation in the tourism industry are being hindered and may therefore pose challenges for Indonesia's growing reliance on international visitors. Sharing economy practices are generally 
regarded to allow host communities to increase personal benefits through tourism. Yet they are often limited to more developed and urban areas of the country where transport (Wahyuningtyas, 2016, Djajadikerta et al., 2017) and accommodation (Wahono and Kartika, 2017) are most widely integrated. Airbnb especially is suggested to provide opportunities for host communities, urban as well as rural, to benefit economically from tourism (Akbar and Andrawina, 2019) and further engage with the industry - yet the potentially transformational effects of the sharing economy on tourism actors including hosts require more attention (Tussyadiah and Sigala, 2018).

\section{Accommodation Sharing}

The sharing economy is arguably one of the most disruptive trends of the past decade. Also known by the terms 'collaborative consumption' or 'peer to peer economy', it is based upon the sharing of goods and services while prioritizing accessibility over ownership (Schor and Fitzmaurice, 2015). Meelen's definition of the sharing economy of 'consumers granting each other temporary access to their underutilized physical assets ("idle capacity"), possibly for money' (Böcker and Meelen, 2017) indicates that financial payment is not a necessary component, although especially Airbnb as a monetary service has received most attention thus far. The rise of the sharing economy in tourism is frequently attributed to visitors' increasing desire for authenticity (Yeoman et al., 2007, Cohen, 2015). Especially accommodation sharing is argued to provide more authentic and genuine (Liang et al., 2017, Guttentag and Smith, 2017, Steylaerts and Dubhghaill, 2012) 'back stage experiences' (MacCannell, 1973) due to the social connections between locals and visitors (Chen, 2012). Interactions with local hosts (Guttentag, 2015), access to accommodation outside of tourist-focused areas (Maitland, 2013) as well as insight into locals' lives (Steylaerts and Dubhghaill, 2012) all contribute to the popularity of especially accommodation sharing.

Cheng (2016) identified that existing sharing economy research is concerned with either its business aspect, its nature, or its connection to sustainability. The focus is predominantly on tourists, and what little is known about hosts is examined through the lens of the guest. For example, an analysis of guest reviews showed that collaborative social practices between hosts and guests strongly contribute to visitors' positive perceptions (Johnson and Neuhofer, 2017). The host experience, on the other hand, remains unexplored. Further attempts to include the host perspective was then limited to their responses to guest reviews (Camilleri and Neuhofer, 2017), therefore evaluating public reactions on a commercialised platform only. Only few studies have adopted a multi-actor approach (e.g. Böcker and Meelen, 2017, Dillahunt and Malone, 2015, Lampinen and Cheshire, 2016), yet these are seldom placed firmly within a tourism context. In addition, most research predominantly explored only the motivations of providers, although Matzner et al. (2015) clearly call for a distinction between motivations to use 
and motivations to provide. Sadhya et al. (2018) also acknowledge the importance of social capital amongst the host-guest relationship.

Interestingly, this distinction between hosts and guests appears less visible in research that has specifically examined Couchsurfing, the sharing economy portal that provides the context of this research. Couchsurfing is an online sharing accommodation portal where community members offer each other free accommodation in their homes (Chen, 2012) while promoting the positive impact of cross-cultural exchange and mutual respect (Couchsurfing, 2019). Reciprocity is a crucial component of Couchsurfing (Geiger et al., 2018), as the platform encourages its members to not only be a guest in other Couchsurfers' homes but also function as a host themselves (Molz, 2012). It can be assumed that hosts and guests within Couchsurfing, which is based on the values of kindness, curiosity, sharing and connections (Couchsurfing, 2019), differ from those participating in monetary and thus more commercialised networks such as Airbnb. It has been shown that 'people participate most in the aspects of a system that address their motives' (Bellotti et al., 2015). Couchsurfing emphasizes meaningful personal encounters (Molz, 2012), thus placing the host-guest interactions in the center of the experience. Kim et al. (2018) examined motivations to function as a Couchsurfing host within a European metropolitan context and identified reciprocity as well as social interactions as the main drivers. They suggest that hosts' prior travel experiences that may not be accessible to hosts in emerging countries have shaped their participation. Further, a variety of related impacts from participating in Couchsurfing have been reported, including personal transformation based on self-development as well as personal reflection and construction (Decrop et al., 2017). It is found that these individual transformations can positively contribute to subsequent societal transformation (Decrop et al., 2017, Picard and Buchberger, 2013), in line with Couchsurfing's mission to make the world a better place by establishing connections through travel (Couchsurfing, 2019).

However, even in the case of a network based on generalized reciprocity, findings relate predominantly to people's experiences as guests while the host perspective remains less visible (Geiger et al., 2018). This is concerning, as the potential impacts of Couchsurfing in particular and the sharing economy in general remain underexplored. After all, it is suggested that Couchsurfing can positively contribute to tourism in areas that are traditionally less favoured (Decrop et al., 2017), leading to increased benefits in disadvantaged regions. Further, the sharing economy provides opportunities for participants to access otherwise unattainable resources, acquire new knowledge and increase employment opportunities (Dillahunt and Malone, 2015). Yet others argue that the sharing economy largely benefits those with certain amounts of existing capital, thus providing a space for only the already privileged (Dredge and Gyimóthy, 2015). This paper will provide insight into the motivations, social practices and perceived value outcomes and impacts of Couchsurfing hosts in Indonesia to fill this gap by utilizing the concept of value co-creation. 


\section{Value Co-Creation}

Value co-creation's core component of a 'reciprocal and mutually beneficial relationship' (Vargo et al., 2008) applies to both the sharing economy in general and Couchsurfing in particular. The service-dominant logic based concept of value co-creation postulates that value will be determined and emerge through the integration and application of operant and operand resources in collaboration between all social actors (Vargo and Lusch, 2008). While originally developed in a service marketing context, value co-creation's collaborative nature lends itself to socio-psychological applications as well (Campos et al., 2018). Co-creation in tourism studies can thus be defined as 'a process of interrelated interactions and activities that connects the tourist and other actors, and experiences are the context in which those interactions and activities occur' (Campos et al., 2018). This definition implies that cocreation is a context wherein a social actor engages with others through interactions and active participation. The co-created value then emerges as a result of interaction, active participation, and collaborative effort that build the experience (Agrawal and Rahman, 2015, Saarijärvi et al., 2013). Perceived value outcomes are then dependent upon the individual's position within the social context (Edvardsson and Gudmundur, 2011). The perspective that determines which social actor stands in the centre of value co-creation is flexible, it is thus a suitable as well as previously tested (Camilleri and Neuhofer, 2017, Johnson and Neuhofer, 2017, Lan et al., 2017) framework to explore the accommodation sharing experience from the perspective of hosts.

This paper will apply Campos et al.'s (2018) original experiencescape-based value co-creation framework to hosts to examine the Couchsurfing hosting experience. Campos et al. (2018) describe the co-creational relationship between social actors during tourism-based encounters within the 'experiencescape'. In the centre stands a social actor who engages mentally and physically in active participation and interaction with other subjects and environment in the destination. This interactive relationship then results in psychological states and processes such as sensations, perceptions, images, feelings and emotions. The experiencescape integrates further influential dimensions into the cocreation experience. Labelled as influencers, these dimensions consist of both operand and operant resources, which can be contributed, managed and harnessed to influence the lived co-creational experience. Based on this socio-psychological interpretation of value co-creation, this research explores the interaction and participation based social practices in Couchsurfing from the host perspective. Further it examines the resulting value outcomes while taking into account the integrated resources as well as hosts' underlying motivations to complement existing research.

This value co-creation framework has been proven suitable in exploring tourism-based value co-creation from a social sciences perspective (Reichenberger, 2017, Pham and Truong-Dinh, 2018, Antón et al., 2018). It is especially suitable to explore participants' engagement, experiences and 
interactions with other social actors based on its context of the tourist experience. It acknowledges especially the social interactions and collaborative participation that function as micro practices to cocreate value without being embedded in an economically oriented service context. The following section will now outline the social constructivist based qualitative methodology.

\section{Methodology}

In line with the focus on interaction and participation based value co-creation, this study's methodology is based upon a social constructivist paradigm, where 'the construction of the social world is seen as occurring through a shared process of communication and social interaction' (Hammersley, 2012). Individuals seek to understand the world they live in and develop subjective meanings that correspond to their experiences (Creswell and Poth, 2017) through interaction with others (Burr, 2018, Small, 1999). Further, social constructivism is concerned with the social practice individuals engage in and their interaction with others, focusing on the meaning-making activities between individuals (Pernecky, 2012). Qualitative methods were thus employed, as they are considered less likely to decontextualize the experience and account of participants (Burr, 2018).

First, semi-structured personal in-depth interviews were conducted with 20 Couchsurfing hosts in Indonesia. The sample size was determined based upon the following considerations: a perceived saturation of information by the researcher as suggested by Green and Thorogood (2018) and the availability of potential research participants within time constraints around the period of data collection. Research participants had to fulfil the following criteria: Registration as a potential host, at least one guest reference, Couchsurfing platform activity within the last six months, and located on the islands of either Bali or Java to ensure accessibility by the researcher. This led to findings not being representative of less developed tourist regions within Indonesia. These population characteristics were used to filter suitable participants through the Couchsurfing website. Using simple random sampling, all suitable profiles were contacted through the platform by the researcher with information about and an invitation to participate in the research. Face-to-face interviews between 30 and 60 minutes were then conducted, using interview guidelines that included open and flexible questions addressing all components of the value co-creation process as well as the underlying motivations to host. To ensure the interviews' alignment with social constructivism, participants were encouraged to first narrate their last experience as a host without further prompts to let their lived realities emerge uninfluenced by prior theory and the researcher.

The opportunity to conduct a focus group emerged through one interview participant who organised a weekly informal gathering for members of the Couchsurfing community located in Yogyakarta, Java. An invitation was extended to the researcher to join the next weekly meeting and conduct a focus group with interested participants afterwards. The six focus group participants were all 
local and experienced Couchsurfing hosts. Throughout the focus group, the interview guidelines were applied to enable the narration of lived experiences. Their focus was also expanded beyond individual hosting experiences to also examine the cumulative value outcomes of hosting and community membership. Due to the similarities in contents and structure among interviews and focus group, both datasets were analysed collectively.

The 20 interview participants were aged between 20 and 35 years. Equal gender distribution was achieved, thus reducing potential gender bias. Ten participants were located in Bali, eight in Yogyakarta and the remaining two in Bandung. This reflects three of the touristically most developed locations and also densely populated places within Indonesia; results of this research may therefore not represent the experiences of Couchsurfing hosts in more remote or rural regions. The six focus group participants were all male, located in Yogyakarta, and aged between 21 and 30.

After transcription, data was analysed following a qualitative thematic analytical approach to ensure that data analysis would be able to adhere to the social constructionist nature of the research (Braun and Clarke, 2006). Thematic analysis is, at its core, inductive and allows for emergent themes to accurately represent the phenomenon itself as opposed to the theory that guided research (Fereday and Muir-Cochrane, 2006, Daly et al., 1997). Five steps were implemented, namely (1) data familiarisation, (2) generating initial codes, (3) searching for themes, (4) reviewing themes, and (5) defining and naming themes (Braun and Clarke, 2006).

Stage (1) data familiarisation was achieved by reading transcripts several times across a oneweek period while noting down possible codes and themes that stood out. For stage (2), generating initial codes, transcripts were imported into NVivo 11. Here, the first three codes developed represented the chronological progress of host-guest interactions: before hosting, during hosting, and after hosting, in line with the research's aim to explore antecedents, process and outcomes of hosting experiences. A fourth code, non-temporal, was added to account for data that represented more generalised transcript components, such as perceptions of Couchsurfing as a system. A fifth code, guest experiences, included participants' prior experiences as a Couchsurfing guest. The sixth and final code, personal background, then included personal information about participants such as personal circumstances. All transcript information was assigned to one or several of these initial six codes which were created as parent nodes within NVivo and provided the foundation for stage (3): searching for themes within the parent nodes. In line with the social constructivist paradigm, themes within the parent nodes were identified not deductively based on academic literature but inductively from the data itself. Common patterns within the data were identified and labelled, subsequently using hand-drawn mind maps to identify initial overlaps across and interdependencies between themes. These themes were entered into NVivo as child nodes, leading to the first coding results that provided additional structure to the initial parent nodes. In step (4), themes were reviewed to ensure all those identified within stage 3 accurately reflect their 
meaning. Here, some themes were merged (e.g. 'paying forward' and 'reciprocity' were merged to 'altruism'), and others were grouped as sub-themes underneath a newly established child node (e.g. a categorization of the different operant resources). Stage (5) then consisted of defining and naming these themes. Here, themes were compared to previously examined literature to identify connections and renaming them to clearly establish their connections with value co-creation as the underlying framework. For example, the initial parent node 'before hosting' was divided into two new parent nodes 'motivation' and 'guest selection'. 'During hosting' was renamed to 'social practices', and 'after hosting' was renamed to 'value outcomes'. This led to the final analytical framework which provided the foundation for the following presentation of findings (figure 2). It includes the parent nodes (main themes) as headings and their corresponding child nodes (codes) in a format that displays their interdependencies.

\section{INSERT FIGURE 1 HERE}

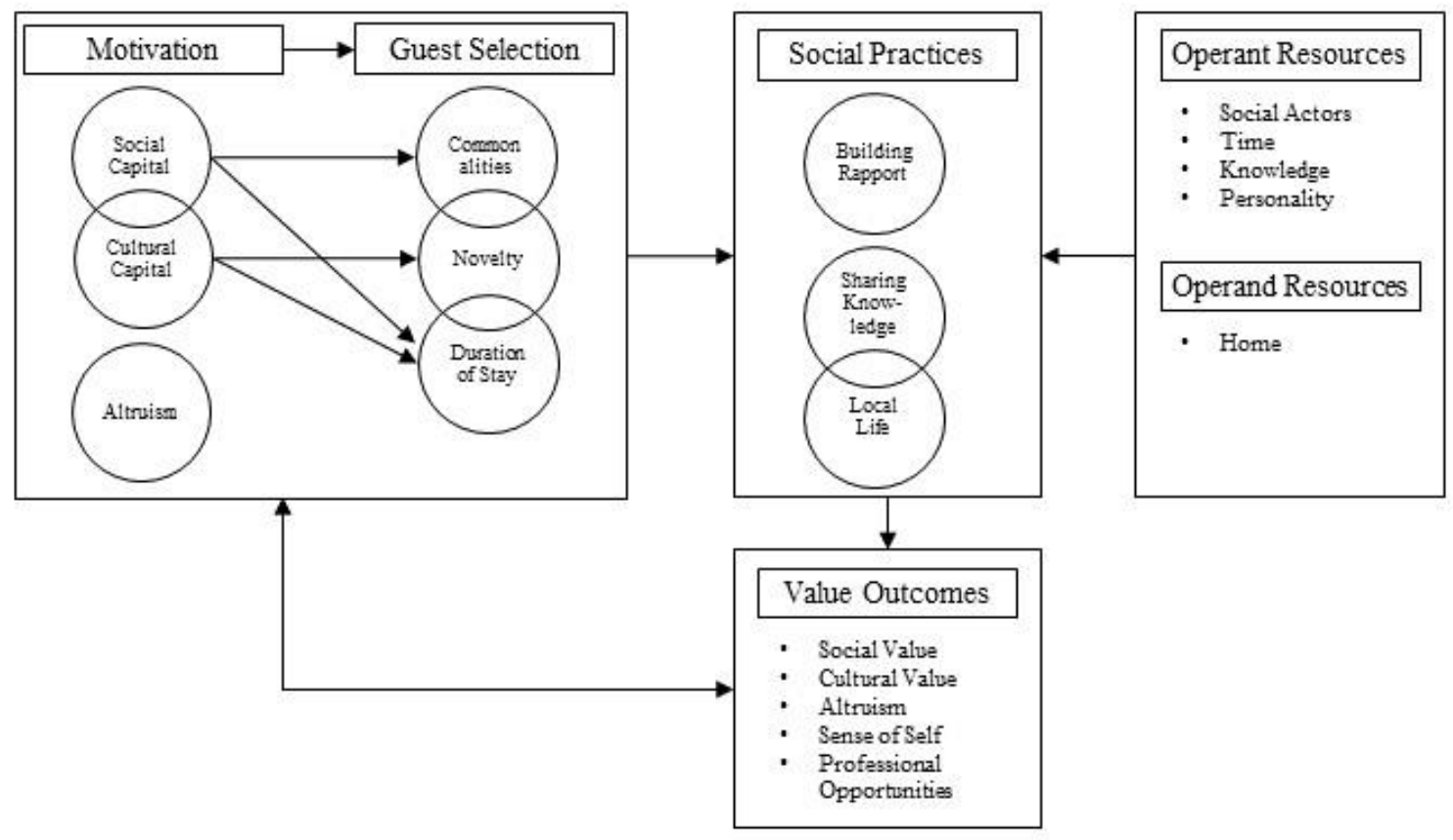

The following section will now present and discuss the findings of the research, starting with participants' motivations to host. Further, social practices will be presented, followed by the value outcomes of hosting in Couchsurfing in Indonesia. 


\section{Findings}

\section{Hosting Motivations}

When exploring the motivations of Indonesian Couchsurfing hosts only intrinsic motivations emerged, likely due to the platform's non-commercial nature that excludes payment. Social and cultural capital emerged as the two dominant motivations, with social capital including 'connections' as well as 'altruism'.

Social capital relates to the benefits that individuals gained from hosting Couchsurfers in their homes. Here, the opportunity to establish connections with other people was important for all participants, confirming previously identified social motivations (Böcker and Meelen, 2017, Schor and Fitzmaurice, 2015). While some regarded these connections somewhat superficially, many were motivated to host to improve their personal wellbeing by reducing loneliness and creating connections - a motivation previously unidentified within sharing economy (Rosen et al., 2011).

I just happened to break up with my fiancée at that time. (...) When I moved to this city, Ifelt so lonely and so heartbroken. My family suggested to me to join Couchsurfing and meet people from there, distract me from having those negative thoughts, I am not that lonely.

Altruism emerged as a social capital related motivation as suggested by Hamari et al. (2016) and Kumar et al. (2018). Providing accommodation without financial incentives provided participants with a sense of achievement through valuable contributions - not as an accommodation provider but as a 'helper'.

If someone asks for help, help, we do not need to consider who is this person asking for help and whether our deeds will be paid or be exchanged into something else. Those sending requests to stay for free are those in needs, maybe they need the help of settling in a new destination. You know, travel is costly.

While some simply enjoyed helping others, the reciprocal nature of Couchsurfing (Molz, 2012) was also evident through altruism (Trivers, 1971). Several participants were not only hosting but also used Couchsurfing as guests during previous travels. Grateful for the hospitality received as a guest, they hosted to return the kindness. Similarly, the notion of 'paying forward', doing good in the hopes that it will return to them indirectly, constituted another sense of reciprocity.

The reason for doing it is because I am paying forward. I am doing this with the hope that if someone I love or care about needs help, there will be someone to help him or her. I believe in Karma.

In addition to social capital, participants were also strongly motivated by the acquisition of cultural capital. This, especially in the form of knowledge, has also been found to be important to 
guests. For them it was predominantly local insight that was desired (Schuckert et al., 2018, Guttentag et al., 2018), however the host interpretation of knowledge differs. The type of cultural capital participants hoped to acquire varied and included intercultural communication, the development of language skills, and getting to know more about the world through interacting with guests. While no monetary exchange was desired, hosts hoped for the sharing of operant resources, sometimes in lieu of financial compensation.

I expect they have something I can learn, something that they can share. Just consider it a way to pay the services I have given to them. I know they are all free financially, but they can pay the services through the knowledge they have.

In most cases, participants were driven by a combination of social and cultural capital motivations, while only two reported purely altruistic motivations. In these cases, every request to host was accepted unconditionally, whereas all other participants were selective about which guests to host to ensure that the hosting experience fulfils underlying motivations. While prior research has identified perceived trust in selecting both guests and hosts in financial accommodation sharing (Ert et al., 2016, Mittendorf, 2016), most host participants selected their guests according to their subjective consideration of cost and reward. Guest profiles allowed participants to evaluate their potential compatibility with the characteristics of the guest, and the duration of stay must be sufficient in fulfilling these motivations (Schuckert et al., 2018).

If you are only staying for one day, it is not Couchsurfing. They are just looking for free places. Why do not they go to a hostel? Because what I know in Couchsurfing, you have to share, you must have interactions with your host. By staying overnight, what interactions can you get?

Those participants for whom social capital was considered more important then continued to elaborate that they desired some commonalities with the potential guest. If participants expressed that they valued predominantly the acquisition of cultural capital, they were especially looking for novelty in guests' personal background.

Before they arrived, they had to send an email, and I had to correspond several times even though only via email. If there was not something in common between us, it was better to decline than having boring conversations during the stay.

I am a quite selective host. Let us say he had experience about something, let us say he works in an NGO, volunteers, is he a marine biologist? I want to know the world of others, and from them, I can learn.

In summary, Couchsurfing hosting motivations confirm prior research that highlights their intrinsic nature through social and cultural capital, although interpreted in different ways than guests. Careful guest selection occurs based on criteria that correspond to dominant motivations, constituting a 
conscious effort to reap maximum benefits and rewards from the hosting experience, thus suggesting the application of the underlying principles of social exchange theory (Cropanzano and Mitchell, 2005).

\section{Social Practices}

This research then explored the social practices during the stay. Taking into account the conscious guest selection from a cost-reward perspective, it is not surprising that a close link between motivations and social practices was identified. While purely altruisticially motivated hosts were found to engage less with their guests, participants with social and cultural capital related motivations designed their social practices with the aim of fulfillment. Three types of sometimes overlapping social practices were identified: 'building rapport', 'sharing knowledge', and to a lesser extent 'local life'. While these do present some similarities with social practices as reported by Airbnb guests (Johnson and Neuhofer, 2017), the main themes that emerged from the host perspectives were less about 'what' these social practices included but 'why' they engaged in them.

In value co-creation practice, every interaction with the aim to establish connections with the guest is categorized as building rapport. Participants considered the way in which the guest is welcomed as an altruistic act that, at the same time, provides the foundation for further, more meaningful interactions.

I will pick them up. From my previous experience as a guest, being picked up by host means something (...) It means something, especially for someone who comes to the city for the first time and they do not know what the city looks like.

Further throughout the stay, participants placed a high value talking with their guests - often within their home as an operand resource where feelings of familiarity can be established (Zuev, 2012). With increasing familiarity, conversation topics would become more personal and extend from participants' more superficial motivation to socialise to their wellbeing related motivations.

We talked about family, his bad relationship with his brother, but they made up while I did not.

That is one of the reasons why I do Couchsurfing. It is easier to talk about personal life with the stranger because they do not judge, they do not know you or the people that we talked about.

Throughout the stay, many rapport-related social practices revolved around the creation and consumption of food (Schuckert et al., 2018). Food fulfils a variety of purposes: a context that allows for integration in hosts' day-to-day activities, an opportunity for intercultural exchange, and to co-create meaningful encounters between host and guest. 
Sometimes they cook for me. So it was more about having a moment together, laughing together, sharing stories. It is always fun you know, going back from work and someone is waiting for you to eat together.

While this is often an opportunity to get to know each other and establish social connections, it also functions to share knowledge as cultural capital. Further social practices were then specifically designed with this purpose in mind. While this exchange of knowledge is often structured to be beneficial to mainly the host, it also includes reciprocal components where both hosts and guests alike provide operant resources to the co-creational practices.

When she went home, she talked a lot with my father about Islam. My father was a religion teacher, and they had a serious discussion. She said that she got to know more about Islam by talking to my dad than by spending months, even years, maybe reading about Islam in a book. My sister and I have a target in two or three years to go to El Camino de Santiago. There was my Couchsurfing guest who has followed the journey, and he could tell me everything in detail. I can't even find it through Google.

Exploring the local area is considered part of guests' desire for authentic experiences (Johnson and Neuhofer, 2017). Local life for hosts, however, fulfilled two functions simultaneously. It provided the spatial and topical context to share further knowledge while also allowing hosts to further their altruistic contributions and integrate their own operant resources.

Celebrating Eid al-Fitr, I included them in the preparation. We went to the market, made a ketupat [rice wrapped in coconut leaves], we ate together, and after that, we went to see Takbir [a parade of celebration]. I mean that's what locals do, right?

Couchsurfing hosts thus created their social practices in ways that would allow them to maximise motivation-related sought benefits. Motivations thus play a significant role in shaping social practices that appeared to be predominantly determined by hosts. These social practices ideally correspond to several motivations at once, most importantly establishing new connections and sharing/acquiring cultural capital in the form of knowledge. Hosts would contribute both operand and operant resources to these social practices. Operant resources consist of their personality, the time they invest, their own knowledge, and other social actors they include. Operand resources then refer predominantly to hosts' own home, as it provides a familiar and safe space for them that allows them to create rapport free from distractions. 


\section{Value Outcomes}

Based on the clear alignment of social practices with original motivations, it is not surprising that many of the reported value outcomes for hosts relate to these also. Here, we can distinguish between 'social value', 'cultural value', 'altruism', as well as the two additional value outcomes of 'sense of self' and 'professional opportunities'.

During the stay, the presence of and interactions with guests create value through improved wellbeing and personal connections. Social motivations were relevant in selecting appropriate guests, directed a variety of co-created social practices, and subsequently - if successful - resulted in benefits. While often this social value is temporally restricted to the duration of the stay, at other times it extends beyond this.

We are still in contact now. At least once a week we communicate and chat through a video call. If we have a problem, we reach out to each other.

Cultural capital as a value outcome is then partly based on the newly acquired knowledge that guests have shared with hosts, but also includes intercultural communication and its transformative impacts. Here, participants often reported an increased understanding of global and individual complexities, and the efforts undertaken to select guests based on their ability to impart new knowledge led to positive outcomes.

I become more open-minded in understanding religion, politics, any issues, understanding why people do things for a religious reason, and so on.

Altruism as a value outcome has been found to be the only value outcome that is not linked to the social practices that occurred throughout the stay. This is enforced by the fact that the two participants who acted purely based on altruistic motivations were non-selective about the hosting requests they accepted. At times they were unable to engage in social practices with their guests at all - this did, however, not affect their perceived value outcomes negatively.

A value outcome that cannot be linked directly to hosts' underlying motivations was an improved sense of self. Couchsurfing, lacking the financial incentive and subsequent obligation to provide certain service standards, removes participation barriers and is more inclusive. This contradicts Dredge and Gyimóthy's (2015) suggestion that the sharing economy only benefits the privileged, with the result that hosts are able to reevaluate their perceptions based on guests' views.

I cursed myself for being born poor and a minority, why was I born in Indonesia? They appreciate my culture, are impressed by the way I live, and this grows my self-confidence in the way I see myself. 
Finally, improved professional opportunities were found to be another value outcome that hosts did not originally anticipate. This often results from knowledge exchange and/or the social practices at the core of the hosting experience.

I have been a tour guide for 5 to 6 months now. After I finished selling mixed rice, I accompanied my guests to explore Bali, from there I had an idea to start working as a guide.

Learning from them [the guests], I have developed many business opportunities. Mainly in paid accommodation sharing, they only need Wi-Fi, air conditioner and hot water, I know their habits.

Reviewing the underlying motivations, value co-creation practice and how resources are integrated into the social interactions, the value outcomes for hosting in Couchsurfing are identified as social value, cultural value, altruism, sense of self and professional opportunities. It can be concluded that values depend on the way hosts select their guests and subsequently co-create their experiences. Both social and cultural capital emerged as motivators as well as value outcomes in a variety of ways, providing insight into the 'other side' of accommodation sharing in a developing country.

\section{Discussion and Conclusion}

This research aimed to explore the value co-creation process in non-monetary accommodation sharing from the host perspective in the emerging country Indonesia. Based on twenty qualitative interviews and one focus group with Indonesian Couchsurfing hosts, their motivations, social practices and subsequent value outcomes are explored. Most research on accommodation sharing is limited to the guest perspective and based in Western settings, and these findings shed light on a hitherto neglected yet essential social actor within an underexplored context.

Couchsurfing's non-monetary nature led to hosting motivations being exclusively intrinsic in nature and encompassed altruism as well as the acquisition of social and cultural capital that, for hosts in developing countries, were often challenging to access. Dredge and Gyimóthy's (2015) assumption that the sharing economy benefits predominantly the privileged is therefore suggested to not be applicable to its non-monetary types. For both hosts and guests the primary motivation was social in nature (Schuckert et al., 2018) and less dependent upon the services provided than in commercial settings (Camilleri and Neuhofer, 2017). The non-reliance on financial contributions, however, also provided hosts with the opportunity to apply an often extensive cost-reward analysis in regard to guest selection as a type of social exchange (Cropanzano and Mitchell, 2005). Prior research has identified trust as a crucial influential factor when engaging in accommodation sharing (Ert et al., 2016, Mittendorf, 2016). For hosts, however, influential factors were driven by their original motivations. The more developed and varied individual motivations were, the more care was taken by hosts to decide 
which hosting requests to accept. A balance between similarities and differences was required to fulfil both social and cultural capital related motivations, whereas guests appear to value similarities higher (Schuckert et al., 2018) as their desire for unfamiliarity may be fulfilled by the unknown destination (Brochado et al., 2017).

Social practices then depend upon motivations - based on altruistic motivations hosts strived to provide guests with the friendly, authentic, and local experiences they sought while simultaneously creating practices that allowed them to build rapport and learn. While guest perceptions of sharing accommodation social practices appear to centre around the types of new experiences (Johnson and Neuhofer, 2017), hosts determined and classified social practices according to how they catered towards their emotional and cognitive needs. Food or local life, experiences in themselves for guests, were regarded as useful contexts within which to co-create relationships and knowledge. They simultaneously allow hosts to take pride in their culture and way of life and re-evaluate their view of what it means to live in a developing country.

Not surprisingly, considering the conscious effort to ensure maximum rewards from the hosting experience, the exploration of value outcomes then confirmed the fulfilment of prior motivations. As suggested prior (Johnson and Neuhofer, 2017), the resources contributing to social practices were directly linked to positive value outcomes. The resource of hosts' home, as well as personalities that were compatible with those of guests, contributed to settings within which rapport and intimacy could develop to create sometimes lasting relationships. Guest resources such as knowledge and prior experiences then positively affected value outcomes linked to hosts' motivations to acquire cultural capital. The integration of host resources through introducing guests to what they consider an authentic version of their lives led to an increasingly positive perception of their own lives, culture and environment. The cumulative engagement as hosts and continuous interaction with international guests also contributed positively to further professional development (Dillahunt and Malone, 2015). This includes the development of soft skills, language skills, and introduction to the tourism industry.

This research has provided additional insight into sharing accommodation experiences by examining the previously neglected role of the host. In doing so, it identifies motivations as a crucial and determining factor for social practices as well as value outcomes. However, prior conceptualisations of value co-creation in social settings has acknowledged the role of motivations only to a limited extent, potentially neglecting a critical component of the process. Further, placing this research in the context of Indonesia as a developing country, it highlights the positive impacts and potential opportunities it can bring to members of the host community, their sense of self, their personal and professional development, and subsequently the wider tourism industry. Prior research suggests that resident perceptions and support of the tourism industry increases with their engagement and perceived personal benefits (Walpole and Goodwin, 2001, Saufi et al., 2014). Considering the rapid growth of Indonesia's 
tourism industry and its increasing distribution across regions (Walpole and Goodwin, 2000), resident support is a crucial factor for success and positive visitor experiences (Lee, 2013). Several barriers to tourism involvement may be able to be reduced through participation in accommodation sharing. Findings showed that communication skills, confidence in visitor interactions, pride in cultural heritage, and control over the perceived authentic depiction of the destination were value outcomes of hosting in Couchsurfing. These also led to increasing understanding and tolerance of visitor behaviour. Not all participants have reported Couchsurfing to have a positive impact on their career. Nevertheless, it does have the potential to increase awareness, knowledge, and highlight previously unidentified opportunities while making tourism-related benefits more accessible to wider parts of the community. Findings of this research may thus be beneficial for tourism planning and development in emerging countries. Public encouragement and support of tourism-related sharing economy models, in particular accommodation sharing, will allow communities to gain a variety of benefits from increasing visitor numbers that go beyond simply economic profit while allowing access to social and cultural capital that may allow for easier entry to the growing tourism industry.

However, this research was limited by its unequal distribution across the country where popular tourist centres were the focus. The unique cultural characteristics of Indonesia especially in regard to altruism linked to karma may reduce the transferability of these findings to other contexts. Future research could therefore focus on exploring host perspectives in Western countries where especially cultural capital can be considered more accessible. We recommend further attention to be paid to, for example, social capital theory or the theory of altruistic sharing to gain a greater understanding of role, dimensions and influential factors of identified motivations. A more inclusive approach to sharing economy experiences could also include studies that take into account host and guest perspectives of the same encounter. This would help better understand how actors negotiate and co-create experiences co-operatively. It is hoped that this paper encourages a more comprehensive and holistic approach to future sharing economy research that acknowledges actors' socio-cultural and economic context. 


\section{References}

AGRAWAL, A. K. \& RAHMAN, Z. 2015. Roles and resource contributions of customers in value cocreation. International Strategic Management Review, 3, 144-160.

AKBAR, R. \& ANDRAWINA, L. 2019. Intention determination of sharing economy business provider in the theory of planned behavior model using partial least square (study case: Airbnb Indonesia). Atlantis Highlights in Engineering, 2, 382-386.

ANTÓN, C., CAMARERO, C. \& GARRIDO, M.-J. 2018. Exploring the experience value of museum visitors as a co-creation process. Current Issues in Tourism, 21, 1406-1425.

BELlotTI, V., AMBARD, A., TURNER, D., GOSSMANN, C., DEMKOVA, K. \& CARROLL, J. M. 2015. A Muddle of Models of Motivation for Using Peer-to-Peer Economy Systems. 33rd Annual ACM Conference on Human Factors in Computing Systems Seoul, Republic of Korea.

BÖCKER, L. \& MEELEN, T. 2017. Sharing for people, planet or profit? Analysing motivations for intended sharing economy participation. Environmental Innovation and Societal Transitions, 23, 28-39.

BRAUN, V. \& CLARKE, V. 2006. Using thematic analysis in psychology. Qualitative Research in Psychology, 3, 77-101.

BROCHADO, A., TROILO, M. \& SHAH, A. 2017. Airbnb customer experience: Evidence of convergence across three countries. Annals of Tourism Research, 63, 210-212.

BURR, V. 2018. Social constructionism, Singapore, Springer.

CAMILLERI, J. \& NEUHOFER, B. 2017. Value co-creation and co-destruction in the Airbnb sharing economy. International Journal of Contemporary Hospitality Management, 29, 2322-2340.

CAMPOS, A. C., MENDES, J., DO VALLE, P. O. \& SCOTT, N. 2018. Co-creation of tourist experiences: a literature review. Current Issues in Tourism, 21, 369-400.

CHEN, D.-J. 2012. Global concept, local practice: Taiwanese experience of CouchSurfing. Hospitality \& Society, 1, 279-297. 
CHENG, M. 2016. Sharing economy: A review and agenda for future research. International Journal of Hospitality Management, 57, 60-70.

COHEN, E. 2015. Tourism, Leisure and Authenticity. Tourism Recreation Research, 35, 67-73.

COLE, S. 2012. A political ecology of water equity and tourism: A case study from Bali. Annals of Tourism Research, 39, 1221-1241.

COUCHSURFING. 2019. About us [Online]. Available: https://www.couchsurfing.com/about/aboutus/ [Accessed 19 September 2019].

CRESWELL, J. W. \& POTH, C. N. 2017. Qualitative inquiry and research design: Choosing among five approaches, Los Angeles, SAGE Publications Inc.

CROPANZANO, R. \& MITCHELL, M. S. 2005. Social exchange theory: An interdisciplinary review. Journal of Management, 31, 874-900.

DALY, J., KELLEHEAR, A., GLIKSMAN, M. \& DALY, K. G. 1997. The public health researcher: A methodological guide, Melbourne, Oxford University Press

DECROP, A., DEL CHIAPPA, G., MALLARGÉ, J. \& ZIDDA, P. 2017. “Couchsurfing has made me a better person and the world a better place": the transformative power of collaborative tourism experiences. Journal of Travel \& Tourism Marketing, 35, 57-72.

DILlahunT, T. R. \& MALONE, A. R. 2015. The Promise of the Sharing Economy among Disadvantaged Communities. 33rd Annual ACM Conference on Human Factors in Computing Systems Seoul, Republic of Korea.

DJAJADIKERTA, H., SUSAN, M. \& DJAJADIKERTA, R. 2017. Antecedents of Customer Intention in Using Online Shared Motorcycle Taxi Service in Indonesia. Advanced Science Letters, 23, 8617-8622.

DREDGE, D. \& GYIMÓTHY, S. 2015. The collaborative economy and tourism: Critical perspectives, questionable claims and silenced voices. Tourism Recreation Research, 40, 286-302.

EDVARDSSON, I. R. \& GUDMUNDUR, K. O. 2011. Knowledge management and value creation in service firms. Measuring Business Excellence, 15, 7-15. 
ERNAWATI, N. M., SANDERS, D. \& DOWLING, R. 2017. Host-Guest Orientations of Communitybased Tourism Products: A Case Study in Bali, Indonesia. International Journal of Tourism Research, 19, 367-382.

ERT, E., FLEISCHER, A. \& MAGEN, N. 2016. Trust and reputation in the sharing economy: The role of personal photos in Airbnb. Tourism Management, 55, 62-73.

FEREDAY, J. \& MUIR-COCHRANE, E. 2006. Demonstrating rigor using thematic analysis: A hybrid approach of inductive and deductive coding and theme development. International Journal of Qualitative Methods, 5, 80-92.

GEIGER, A., HORBEL, C. \& GERMELMANN, C. C. 2018. "Give and take”: how notions of sharing and context determine free peer-to-peer accommodation decisions. Journal of Travel \& Tourism Marketing, 35, 5-15.

GRACI, S. 2017. Communities As the Avenue for Change: A Case Study of Gili Trawangan, Indonesia. Global Conference on Services Management. Volterray, Italy.

GREEN, J. \& THOROGOOD, N. 2018. Qualitative Methods for Health Research, London, Sage.

GUTTENTAG, D. 2015. Airbnb: disruptive innovation and the rise of an informal tourism accommodation sector. Current Issues in Tourism, 18, 1192-1217.

GUTTENTAG, D., SMITH, S., POTWARKA, L. \& HAVITZ, M. 2018. Why Tourists Choose Airbnb: A Motivation-Based Segmentation Study. Journal of Travel Research, 57, 342-359.

GUTTENTAG, D. \& SMITH, S. L. J. 2017. Assessing Airbnb as a disruptive innovation relative to hotels: Substitution and comparative performance expectations. International Journal of Hospitality Management, 64, 1-10.

HAMARI, J., SJÖKLINT, M. \& UKKONEN, A. 2016. The sharing economy: Why people participate in collaborative consumption. Journal of the Association for Information Science and Technology, 67, 2047-2059.

HAMMERSLEY, M. 2012. What is Qualitative Research?, London, Bloomsbury. 
HILLMAN, P., MOYLE, B. D. \& WEILER, B. 2017. Perceptions of Impacts and Development in a Cultural Tourism Hub: Ubud, Bali. In: SAUFI, A., ANDILOLO, I. R., OTHMAN, N. \& LEW, A. A. (eds.) Balancing Development and Sustainability in Tourism Destinations. Singapore: Springer.

JOHNSON, A.-G. \& NEUHOFER, B. 2017. Airbnb - an exploration of value co-creation experiences in Jamaica. International Journal of Contemporary Hospitality Management, 29, 2361-2376.

JUNG, J., YOON, S., KIM, S., PARK, S., LEE, K.-P. \& LEE, U. Social or Financial Goals? CHI Conference on Human Factors in Computing Systems, May 2016 San Jose, USA. 2857-2863.

KIM, S., LEE, K. Y., KOO, C. \& YANG, S.-B. 2018. Examining the influencing factors of intention to share accommodations in online hospitality exchange networks. Journal of Travel \& Tourism Marketing, 35, 16-31.

KUMAR, V., LAHIRI, A. \& DOGAN, O. B. 2018. A strategic framework for a profitable business model in the sharing economy. Industrial Marketing Management, 69, 147-160.

LAMPINEN, A. \& CHESHIRE, C. 2016. Hosting via Airbnb. CHI Conference on Human Factors in Computing Systems San Jose, USA.

LAN, J., MA, Y., ZHU, D., MANGALAGIU, D. \& THORNTON, T. 2017. Enabling value co-creation in the sharing economy: The case of mobike. Sustainability, 9, 1504.

LASSO, A. \& DAHLES, H. 2018. Are tourism livelihoods sustainable? Tourism development and economic transformation on Komodo Island, Indonesia. Asia Pacific Journal of Tourism Research, 23, 473-485.

LEE, J. W. \& SYAH, A. M. 2018. Economic and environmental impacts of mass tourism on regional tourism destinations in Indonesia. Journal of Asian Finance, Economics and Business, 5, 3141.

LEE, T. H. 2013. Influence analysis of community resident support for sustainable tourism development. Tourism Management, 34, 37-46. 
LIANG, L. J., CHOI, H. S. C. \& JOPPE, M. 2017. Understanding repurchase intention of Airbnb consumers: perceived authenticity, electronic word-of-mouth, and price sensitivity. Journal of Travel \& Tourism Marketing, 35, 73-89.

MACCANNELL, D. 1973. Staged authenticity: Arrangements of social space in tourist settings. The American Journal of Sociology, 79, 589-603.

MAITLAND, R. 2013. Backstage behaviour in the global city: Tourists and the search for the 'real London'. Procedia-Social and Behavioral Sciences, 105, 12-19.

MATZNER, M., CHASIN, F. \& TODENHÖFER, L. To Share or Not to Share: Towards Understanding the Antecedents of Participation in IT-Enabled Sharing Services. European Conference on Information Systems, 26 - 29 May 2015 Munster, Germany.

MITTENDORF, C. 2016. What Trust means in the Sharing Economy: A provider perspective on Airbnb.com. 22nd Americas Conference on Information Systems. San Diego, USA.

MÖHLMANN, M. 2015. Collaborative consumption: determinants of satisfaction and the likelihood of using a sharing economy option again. Journal of Consumer Behaviour, 14, 193-207.

MOLZ, J. G. 2012. CouchSurfing and network hospitality: 'It's not just about the furniture'. Hospitality \& Society, 1, 215-225.

PERNECKY, T. 2012. Constructionism. Critical Pointers for Tourism Studies. Annals of Tourism Research, 39, 1116-1137.

PHAM, L.-H. T. \& TRUONG-DINH, B. Q. 2018. An exploratory study of the perception of co-creation experience in the tourism industry: A case study in Danang city, Vietnam. Academy of Marketing Studies Journal, 22, 1-14.

PICARD, D. \& BUCHBERGER, S. 2013. Introduction: Couchsurfing in Lisbon, Tunis and Brisbane. In: PICARD, D. \& BUCHBERGER, S. (eds.) Couchsurfing Cosmopolitanisms. Can Tourism Make a Better World? Bielefeld: transcript Verlag.

REICHENBERGER, I. 2017. C2C value co-creation through social interactions in tourism. International Journal of Tourism Research, 19, 629-638. 
ROSEN, D., LAFONTAINE, P. R. \& HENDRICKSON, B. 2011. CouchSurfing: Belonging and trust in a globally cooperative online social network. New Media \& Society, 13, 981-998.

SAARIJÄRVI, H., KANNAN, P. \& KUUSELA, H. 2013. Value co-creation: theoretical approaches and practical implications. European Business Review, 25, 6-19.

SADHYA, H., SADHYA, V., HIRSCHHEIM, R. \& WATSON, E. Value Co-Creation in Airbnb: a Social Capital Perspective. European Conference on Information Systems, 23 - 28 June 2018 Portsmouth, UK. 51.

SAUFI, A., O'BRIEN, D. \& WILKINS, H. 2014. Inhibitors to host community participation in sustainable tourism development in developing countries. Journal of Sustainable Tourism, 22, 801-820.

SCHOR, J. B. \& FITZMAURICE, C. J. 2015. Collaborating and connecting: the emergence of the sharing economy. In: REISCH, L. A. \& THØGERSEN, J. (eds.) Handbook of Research on Sustainable Consumption. Cheltenham: Edward Elgar.6

SCHUCKERT, M., PETERS, M. \& PILZ, G. 2018. The co-creation of host-guest relationships via couchsurfing: a qualitative study. Tourism Recreation Research, 43, 220-234.

SMALL, J. 1999. Memory-work: a method for researching women's tourist experiences. Tourism Management, 20, 25-35.

STEYLAERTS, V. \& DUBHGHAILL, S. O. 2012. CouchSurfing and authenticity: Notes towards an understanding of an emerging phenomenon. Hospitality \& Society, 1, 261-278.

TOWNER, N. \& MILNE, S. 2017. Sustainable surfing tourism development in the Mentawai Islands, Indonesia: Local stakeholder perspectives. Tourism Planning \& Development, 14, 503-526.

TRIVERS, R. L. 1971. The evolution of reciprocal altruism. The Quarterly Review of Biology, 46, 3557.

TUSSYADIAH, I. P. \& SIGALA, M. 2018. Shareable tourism: tourism marketing in the sharing economy. Journal of Travel \& Tourism Marketing, 35, 1-4. 
UNWTO. 2020. Country profile - Inbound tourism [Online]. Available: https://www.unwto.org/country-profile-inbound-tourism [Accessed 14 January 2020].

VARGO, S. L. \& LUSCH, R. F. 2008. Service-dominant logic: continuing the evolution. Journal of the Academy of Marketing Science, 36, 1-10.

VARGO, S. L., MAGLIO, P. P. \& AKAKA, M. A. 2008. On value and value co-creation: A service systems and service logic perspective. European Management Journal, 26, 145-152.

WAHONO, F. A. \& KARTIKA, E. W. 2017. Consumer Behavior Study On The Acceptance of Airbnb from Consumer in Surabaya, Indonesia. Jurnal Hospitality dan Manajemen Jasa, 5.

WAHYUNINGTYAS, S. Y. 2016. The online transportation network in Indonesia: A pendulum between the sharing economy and ex ante regulation. Competition and Regulation in Network Industries, 17, 260-280.

WALPOLE, M. J. \& GOODWIN, H. J. 2000. Local economic impacts of dragon tourism in Indonesia. Annals of Tourism Research, 27, 559-576.

WALPOLE, M. J. \& GOODWIN, H. J. 2001. Local attitudes towards conservation and tourism around Komodo National Park, Indonesia. Environmental Conservation, 28, 160-166.

WORLD TRAVEL \& TOURISM COUNCIL. 2019. Indonesian Travel \& Tourism growing twice as fast as global average [Online]. Available: https://www.wttc.org/about/media-centre/pressreleases/press-releases/2019/indonesian-travel-and-tourism-growing-twice-as-fast-as-globalaverage/ [Accessed 14 January 2020].

YEOMAN, I., BRASS, D. \& MCMAHON-BEATTIE, U. 2007. Current issue in tourism: The authentic tourist. Tourism Management, 28, 1128-1138.

ZUEV, D. 2012. CouchSurfing as a spatial practice: Accessing and producing xenotopos. Hospitality \& Society, 1, 227-244. 